Asian J. Med. Biol. Res. 2016, 2 (1), 55-61; doi: 10.3329/ajmbr.v2i1.27569

\author{
Asian Journal of \\ Medical and Biological Research \\ ISSN 2411-4472 (Print) 2412-5571 (Online) \\ www.ebupress.com/journal/ajmbr
}

\title{
Article \\ Effects of saline water on health status of pregnant women in coastal regions of Bangladesh
}

Zohirul Islam Rony ${ }^{1}$, Md. Shafiqul Islam Khan ${ }^{2 *}$, Md. Ali Asgar ${ }^{3}$, Musammet Rasheda Begum $^{4}$ and ASM Golam Kibria $^{5}$

${ }^{1}$ Department of Biochemistry and Food Analysis, Faculty of Nutrition and Food Science, Patuakhali Science and Technology University, Patuakhali, Bangladesh

${ }^{2}$ Department of Food Microbiology, Faculty of Nutrition and Food Science, Patuakhali Science and Technology University, Patuakhali, Bangladesh

${ }^{3}$ Department of Physiology and Pharmacology, Faculty of Animal Science and Veterinary Medicine, Patuakhali Science and Technology University, Barisal, Bangladesh

${ }^{4}$ Department of Agricultural Economics and Social Sciences, Faculty of Veterinary Medicine, Chittagong Veterinary and Animal Sciences University, Chittagong, Bangladesh

${ }^{5}$ Department of Anatomy and Histology, Faculty of Veterinary Medicine, Chittagong Veterinary and Animal Sciences University, Chittagong, Bangladesh

*Corresponding author: Md. Shafiqul Islam Khan, Department of Food Microbiology, Faculty of Nutrition and Food Science, Patuakhali Science and Technology University, Patuakhali, Bangladesh. E-mail: msikhan312@yahoo.com

Received: 14 February 2016/Accepted: 10 March 2016/Published: 31 March 2016

\begin{abstract}
Drinking water from natural sources in coastal region of Bangladesh has been contaminated by varying degrees of salinity which have detrimental effects on the health. Pregnancy itself is a crucial time for women and the salinity increases its vulnerability regarding the raising of blood pressure. The study was conducted to evaluate the effect of saline water intake on the health status of pregnant women at Barguna and Patuakhali districts, Bangladesh. Sodium $(\mathrm{Na})$ concentration in urine samples was analyzed and corresponding blood pressure was taken in the diagnostic laboratory. Descriptive statistical analysis showed that Na concentration, systolic and diastolic pressure (BP) was the highest in 2nd trimester followed by 3rd trimester and 1st trimester. Water intake and urine production were the highest in 3rd trimester and increased with age. $\mathrm{Na}$ concentration, systolic and diastolic pressure (bp) was the highest in 3rd parity followed by 2nd parity. Water intake and urine production did not very among parities. Correlation matrix express that sodium concentration has the significant association with the age and the highly significant association with systolic and diastolic blood pressure. In Logistic Regression Model, odds ratio (OR) estimate showed that women with systolic $b p \geq 120$ had 1.109 times greater sodium concentration than with systolic blood pressure of $<120$ and, with diastolic $\mathrm{bp} \geq 80$ contain 1.064 times greater sodium concentration than with diastolic blood pressure of $<$ 80 .
\end{abstract}

Keywords: salinity; pregnant women; sodium concentration; blood pressure

\section{Introduction}

Climate change has direct and indirect adverse impacts on human health through flood, cyclone, and drought, and salinity intrusion in water. In coastal Bangladesh, natural drinking water sources, such as rivers and groundwater are threatened by saltwater intrusion from the Bay of Bengal. Groundwater, crop soils, and many rivers have been increasingly saline from higher tidal waves and storm surges due to climate change impacts (Parry et al., 2007). Estimates indicate that Bangladesh has about a fifth of the total area of country which is affected by salinity. Salinity intrusion from sea water owing to reduction of freshwater flow from upstream is 
expected to be aggravated by climate change and sea-level rise (Khan et al., 2008). About 20 million people in the coastal regions of Bangladesh who extensively depends on rivers, tube wells, and ponds for washing, bathing, and drinking water is affected by varying degrees of salinity (MOEF, 2006). Sodium helps keep the water and electrolyte balance in body. However, high dietary intake of sodium produces detrimental effects on health, specially causing high blood pressure and other associated deleterious outcomes (Chobanian, 2000). Pregnancy is a very critical time for women where any deviation from normal physiology can be more harmful than other time of life. Normally, diastolic and systolic blood pressures tend to fall during mid-pregnancy and then return to normal by week 36 (Thomburg, 2000). As the people of the study area depend mainly on the saline water for regular family use, there may be the increasing chance of high sodium level in urine and rising of blood pressure which may affect the health of pregnant women. Considering the above scenario, the study was undertaken i) to estimate the sodium concentration in urine of pregnant women ii) to identify the correlation of sodium concentration with other variables such as age, parity, trimester, water intake, urine output and systolic and diastolic blood pressure.

\section{Materials and Methods}

\subsection{Selection of the study area}

There are many saline prone areas in Bangladesh such as Patuakhali, Pirojpur, Barguna, Satkhira, Bagerhat, and Khulna. For the study we selected two most salinity prone Barguna and Patuakhali districts.

\subsection{Selection of pregnant women}

A total of 100 pregnant women between 16 and 35 years of age were randomly selected from the study area. Selection was done on the basis of trimester (1st, 2nd \& 3rd) and parity (1st, 2nd \& 3rd).

\subsection{Collection of urine sample}

Health assistants under the supervision of the Community Clinics at study areas regularly identified and monitored all pregnant women between the ages of 16 and 35 years. Pregnant women gave 24-hour urine sample to the local private diagnostic laboratory. A single sample of 24-hour urine production was collected from each woman. Total volume of urine was recorded with proper data on parity and time of gestation period.

\subsection{Measurement of urine output and blood pressure}

After collecting data on water source, parity and gestation period, the water intake and urine output/day were calculated. The blood pressure was measured and the urine was analyzed for sodium concentration.

\subsection{Sodium concentration analysis}

24-hour urine sample from pregnant women were subjected to analyze to determine sodium concentration. Urinary Sodium concentration analysis was done by using electrolyte analyzer machine (EasyLyte Analyzer Machine, made by Germany).

\subsection{Logistic regression model}

A logistic regression model was fitted in the univariate context and least significant value $<0.05$ were considered as candidates for the Multiple Logistic Regression model (Hosmer and Lemeshow, 2000). Logistic regression is a type of probabilistic statistical classification model that can be used to predict a binary response from a binary predictor and for predicting the outcome of a categorical dependent variable based on one or more predictor variables. In this study the dependent variables are systolic blood pressure which categorized as $\geq 120$ and $<120$ and diastolic blood pressure categorized as $\geq 80$ and $<80$.

\section{Results}

The study was undertaken to assess the degree of salinity in drinking water and its effects on the health status of pregnant women in different areas of Barguna and Patuakhali, two coastal districts of Bangladesh.

\subsection{Distribution of pregnant women}

Distribution of pregnant women depending on age groups, parities, and gestation periods are presented in pie charts and bar graphs. 
Table 1. Descriptive statistics of different parameters across trimesters.

\begin{tabular}{|c|c|c|c|c|c|c|}
\hline Trimester & No. of women & Parameters & Mean & $\begin{array}{l}\text { Standard } \\
\text { Deviation }\end{array}$ & Minimum & Maximum \\
\hline \multirow[t]{6}{*}{$1^{\text {st }}$} & 20 & Age (year) & 20 & 4.08 & 16 & 24 \\
\hline & & $\begin{array}{l}\text { Na concentration } \\
\text { (mmol/day) }\end{array}$ & 167.5 & 6.45 & 160 & 175 \\
\hline & & Water intake (L) & 3.13 & 0.75 & 2.25 & 3.75 \\
\hline & & Urine output (L) & 1.13 & 0.25 & 0.75 & 1.25 \\
\hline & & Systolic BP (mmHg) & 115 & 8.16 & 90 & 125 \\
\hline & & Diastolic BP (mmHg) & 82.5 & 8.16 & 70 & 87 \\
\hline \multirow[t]{6}{*}{$2^{\text {nd }}$} & 32 & Age (year) & 23.53 & 4.46 & 18 & 34 \\
\hline & & $\begin{array}{l}\text { Na concentration } \\
\text { (mmol/day) }\end{array}$ & 169.76 & 28.7 & 110 & 240 \\
\hline & & Water intake (L) & 3.44 & 0.7 & 2.5 & 4.75 \\
\hline & & Urine output (L) & 1.12 & 0.16 & 0.75 & 1.25 \\
\hline & & Systolic BP (mmHg) & 128.4 & 10.6 & 100 & 130 \\
\hline & & Diastolic BP (mmHg) & 92.35 & 8.31 & 75 & 95 \\
\hline \multirow[t]{6}{*}{$3^{\text {rd }}$} & 48 & Age (year) & 27.5 & 4.6 & 20 & 35 \\
\hline & & $\begin{array}{l}\text { Na concentration } \\
\text { ( } \mathrm{mmol} / \text { day) }\end{array}$ & 168.83 & 26.73 & 140 & 230 \\
\hline & & Water intake (L) & 3.63 & 0.79 & 2.25 & 4.75 \\
\hline & & Urine output (L) & 1.15 & 0.17 & 0.75 & 1.25 \\
\hline & & Systolic BP (mmHg) & 123.33 & 8.88 & 100 & 130 \\
\hline & & Diastolic BP $(\mathrm{mmHg})$ & 84.58 & 7.82 & 70 & 95 \\
\hline
\end{tabular}

Table 2. Descriptive statistics of different parameters across parity.

\begin{tabular}{|c|c|c|c|c|c|c|}
\hline Parity & $\begin{array}{l}\text { No. of } \\
\text { persons }\end{array}$ & Parameters & Mean & $\begin{array}{l}\text { Standard } \\
\text { Deviation }\end{array}$ & Minimum & Maximum \\
\hline \multirow[t]{6}{*}{$1^{\mathrm{st}}$} & 42 & Age (year) & 21.36 & 3.63 & 16 & 30 \\
\hline & & $\mathrm{Na}$ concentration (mmol/day) & 160.5 & 15.97 & 140 & 190 \\
\hline & & Water intake (L) & 3.46 & 0.66 & 2.25 & 4.75 \\
\hline & & Urine output (L) & 1.14 & 0.15 & 0.75 & 1.25 \\
\hline & & Systolic BP (mmHg) & 117.51 & 7.45 & 100 & 120 \\
\hline & & Diastolic BP (mmHg) & 79.14 & 6.99 & 60 & 80 \\
\hline \multirow[t]{6}{*}{$2^{\text {nd }}$} & 45 & Age (year) & 24.27 & 3.95 & 20 & 34 \\
\hline & & $\mathrm{Na}$ concentration (mmol/day) & 170.33 & 29.32 & 110 & 240 \\
\hline & & Water intake (L) & 3.43 & 0.82 & 2.25 & 4.75 \\
\hline & & Urine output (L) & 1.11 & 0.19 & 0.75 & 1.25 \\
\hline & & Systolic BP (mmHg) & 120.21 & 11.34 & 90 & 130 \\
\hline & & Diastolic BP (mmHg) & 78.53 & 7.75 & 60 & 90 \\
\hline \multirow[t]{6}{*}{$3^{\text {rd }}$} & 13 & Age (year) & 29.21 & 3.95 & 20 & 34 \\
\hline & & $\mathrm{Na}$ concentration ( $\mathrm{mmol} /$ day) & 172.35 & 29.32 & 110 & 240 \\
\hline & & Water intake (L) & 3.43 & 0.82 & 2.25 & 4.75 \\
\hline & & Urine output (L) & 1.11 & 0.19 & 0.75 & 1.25 \\
\hline & & Systolic BP (mmHg) & 125.32 & 11.34 & 90 & 130 \\
\hline & & Diastolic BP (mmHg) & 87.25 & 7.75 & 65 & 90 \\
\hline
\end{tabular}

Table 3. Correlation matrix.

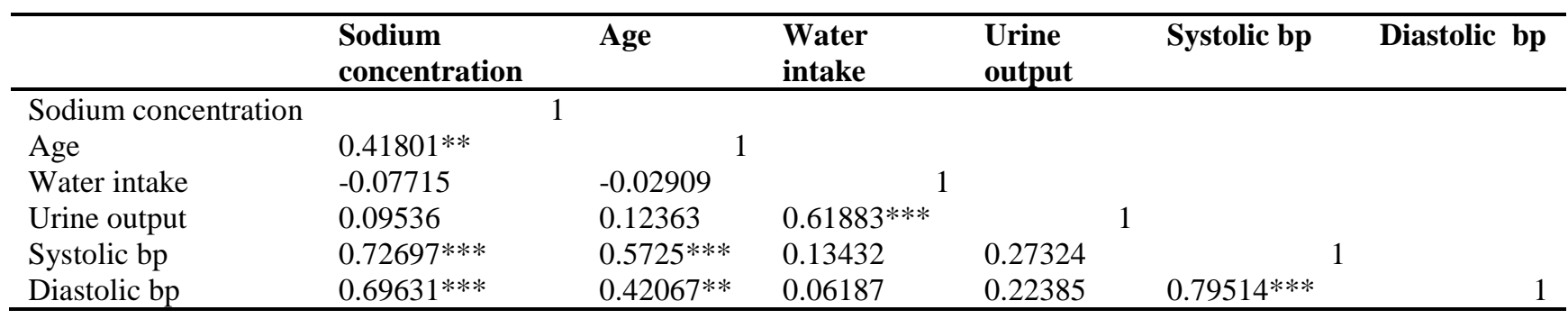


Table 4. Parameter estimates and Standard errors (in parentheses) for systolic and diastolic blood pressure.

\begin{tabular}{llllll}
\hline $\begin{array}{l}\text { Blood } \\
\text { Pressure }\end{array}$ & Parameter & Estimate & Pr $>$ ChiSq & $\begin{array}{l}\text { Odds ratio } \\
(\text { OR })\end{array}$ & $\begin{array}{l}\text { 95\% C.I. for } \\
\text { OR }\end{array}$ \\
\hline Systolic bp & Intercept & $-18.607(7.2199)$ & 0.01 & - & - \\
& Na concentration & $0.1033(0.041)$ & 0.0117 & 1.109 & $1.023,1.202$ \\
Diastolic bp & Intercept & $-11.3311(4.5952)$ & 0.0137 & - & - \\
& Na concentration & $0.0617(0.0263)$ & 0.019 & 1.064 & $1.010,1.120$ \\
\hline
\end{tabular}

No. of persons of different age group

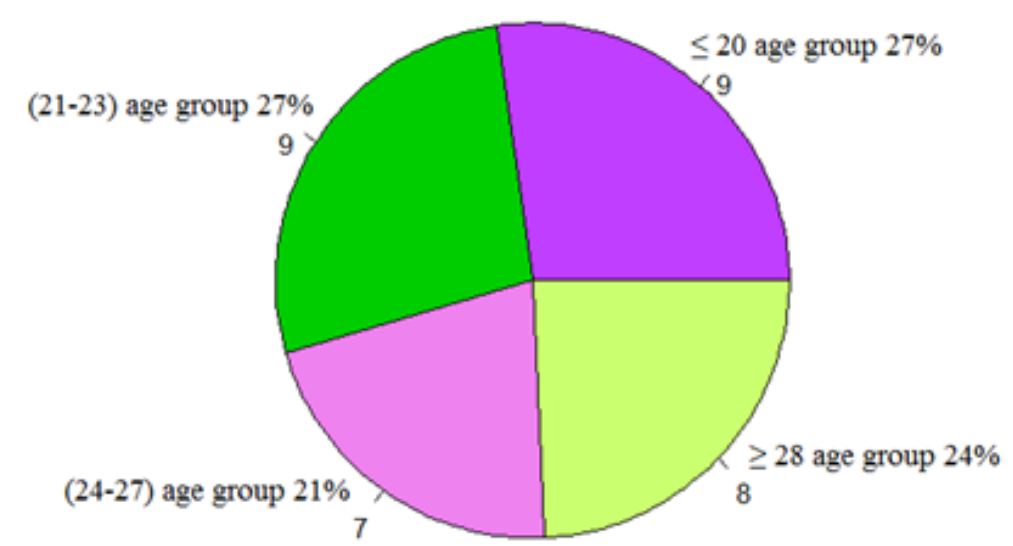

Figure 1. Frequency distribution of pregnant women in different age groups in study area.
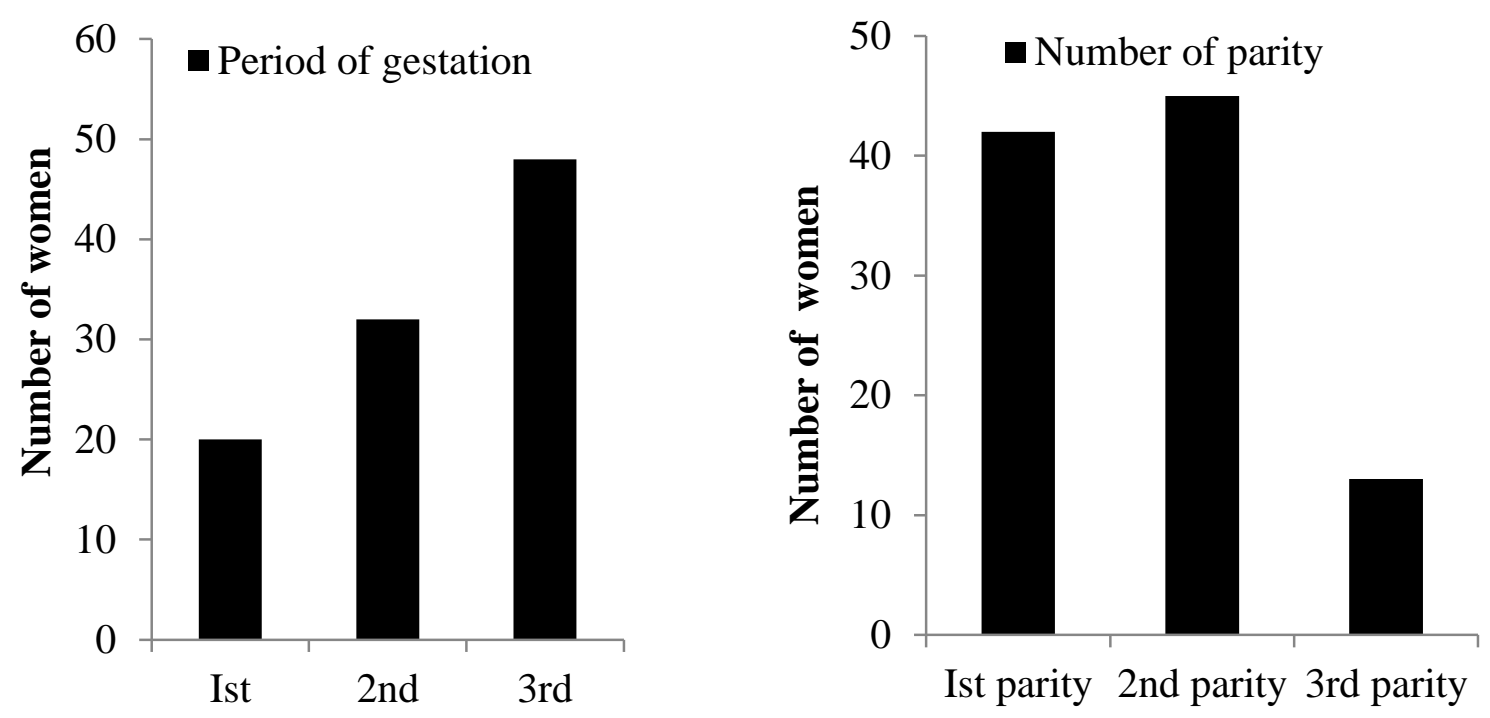

trimester trimester trimester

Figure 2. Number of women of different trimesters and parities. 


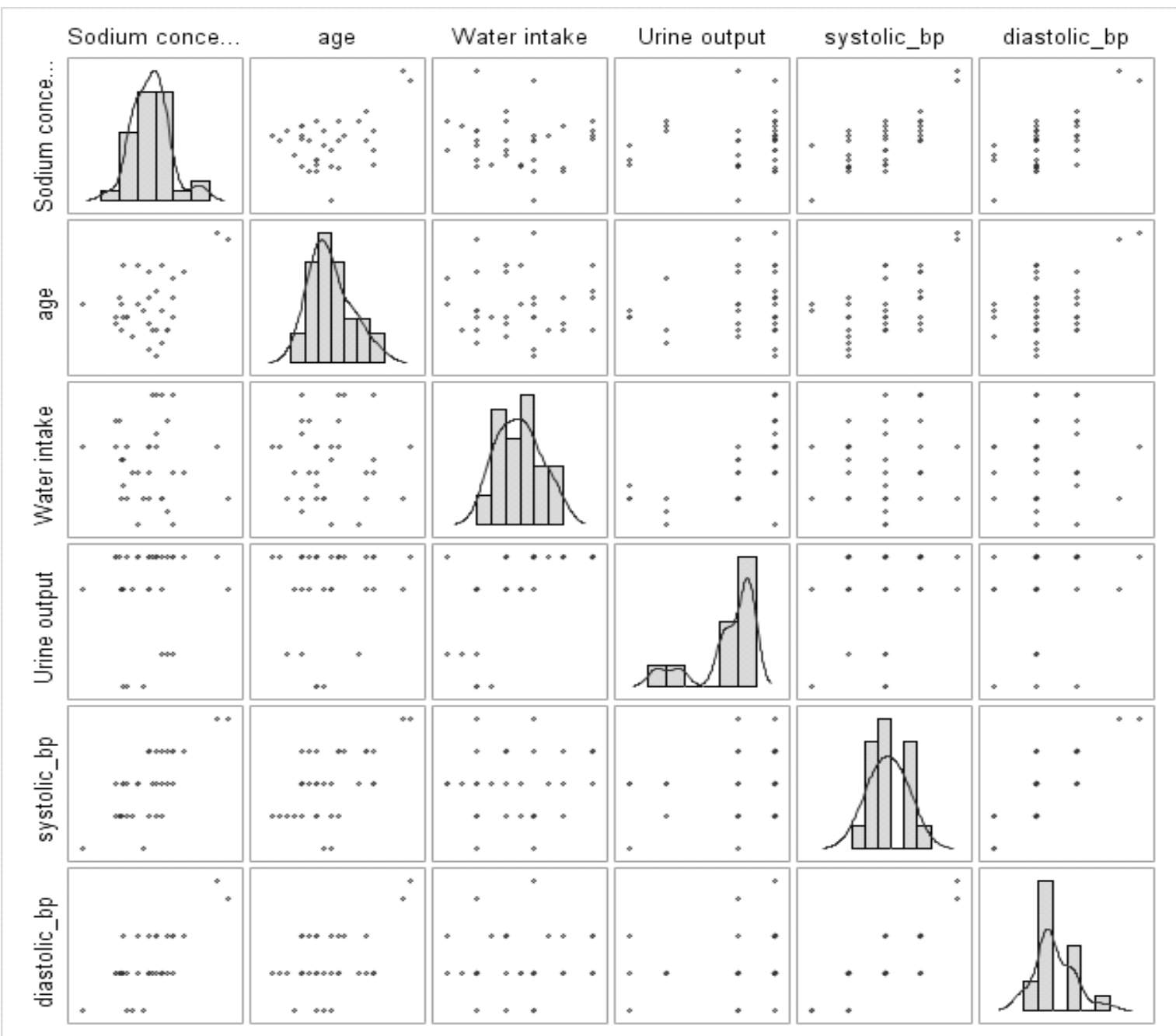

Figure 3. Scatter diagram of different variables.

\subsection{Descriptive statistics of selected parameters at different trimesters and parities}

Table 1 demonstrates the descriptive statistics of age, Na concentration, water intake, urine output, systolic and diastolic pressure at different trimesters. Average age, Na concentration, water intake, urine output, systolic and diastolic pressure were $20.00,167.5,3.13,1.13,115$ and 82.5 for 1 st trimester and $23.53,169.76,3.44,1.12$, 128.4 and 92.35 for 2 nd trimester and, $27.50,168.83,3.63,1.15,123.33$ and 84.58 for $3^{\text {rd }}$ trimester, respectively Table 2 demonstrates the descriptive statistics at different parities. The average age, Na concentration, water intake, urine output, systolic and diastolic pressure were $21.36,160.50,3.46,1.14,117.51$ and 79.14 for 1 st parity and $24.27,170.33,3.43,1.11,120.21$ and 78.53 for $2^{\text {nd }}$ parity and $29.21,172.35,3.43,1.11,125.32$ and 87.25 for $3^{\text {rd }}$ parity, respectively.

\subsection{Correlation among the different variables}

Table 3 and Figure 3 express the correlation among the different variables where sodium concentration had the significant relationship with the age and the highly significant relationship with systolic and diastolic blood pressure.

\subsection{Logistic regression model}

Logistic regression model was fitted for systolic and diastolic blood pressure (bp) separately. All parameters were $>0.05$ level of significance except sodium concentration for both models. Hosmer and Lemeshow goodness of fit test was done. Evidence of chi-square $=4.87$, $\mathrm{p}$-value $=0.68$ for systolic bp and chi-square $=5.28$, $\mathrm{p}$-value $=0.63$ proved that the model fit best. The small $\mathrm{p}$-value $(<0.0001$ and 0.0017$)$ for the likelihood ratio (LR) chi-squared statistic implies that effect of sodium concentration in the model is important for predicting the probability of systolic and diastolic bp. The p-value for sodium concentration effect is smaller than 0.05 for both models. So the $95 \%$ CI for OR excludes 1. In Table 4, parameter estimate of sodium concentration was concluded that the log odds of systolic $b p$ of $\geq 120$ increases, as sodium concentration increases 0.1033 unit. The 
odds ratio (OR) estimate shows that the odds of systolic $b p \geq 120$ for the sodium concentration was 1.109 times greater than the systolic blood pressure of $<120$. Like systolic blood pressure, the parameter estimate of sodium concentration was concluded that the $\log$ odds of diastolic blood pressure of $\geq 80$ increase, as sodium concentration increases 0.0617 unit. The odds ratio (OR) estimate shows that the odds of diastolic $b p \geq 80$ for the sodium concentration was 1.064 times greater than the diastolic blood pressure of $<80$.

\section{Discussion}

Water-related crises are not new problems in Bangladesh. Now Bangladesh is facing environmental and health threat due to man-made and natural factors: increased salinity. It has already had adverse effects on crop productivity and grain production. Now it appears to be a threat to the well- being of communities who live in coastal areas of this low laying nation (Khan et al., 2008).We studied some relationship in terms of effects posed by high salinity in water used by people living in coastal areas. The study indicates that sodium concentration is higher $\left(169.76 \mathrm{mmol} /\right.$ day) in 2 nd trimester than $1^{\text {st }}(167.5 \mathrm{mmol} /$ day $)$ and $3 \mathrm{rd}(168.83$ $\mathrm{mmol} /$ day) trimester. In the case of parity, $\mathrm{Na}^{+}$concentration is higher in $3 \mathrm{rd}$ parity $(172.35 \mathrm{mmol} /$ day) than $1 \mathrm{st}$ ( $160.5 \mathrm{mmol} /$ day) and $2 \mathrm{nd}\left(170.33 \mathrm{mmol} /\right.$ day) parity. For age group, average $\mathrm{Na}^{+}$concentration is higher $(235$ $\mathrm{mmol} /$ day) in the group of of $\geq 28$ years old than other three groups. The normal sodium level of pregnant women becomes lower at 132-140 mmol/L of blood (Tran, 2005). In this study, the Na concentration was found higher as the people of the study area depends mainly on the saline water for regular family use. However, previous study indicated that male and female systolic blood pressures in the high sodium community were not significantly higher than those in the low sodium community. Surprisingly, the observed systolic blood pressures of males in the lower sodium community were higher than those in the high sodium community (Hallenbeck et al., 1981). Another study results indicated that statistically significant and medically important higher BP distributions among the high Na town students relative to their low Na town peers for both systolic and diastolic BP in both boys and girls in Massachusetts (Calabrese \& Tuthill, 1981). Increased sodium concentration in urine and rising of blood pressure may affect the health of mother and future child. In a survey conducted in 2008, higher rates of eclampsia and gestational hypertension in pregnant women living in the southwestern coast of Bangladesh compared with noncoastal pregnant women were hypothesized to be caused by saline contamination of drinking water (Khan et al., 2008). This study denotes that urinary sodium concentration has the significant association with the age and the highly significant association with systolic and diastolic blood pressure. Similar study of dietary intake of salt with high sodium has some detrimental effects of health where evidence proves that high sodium intake is causally related to high blood pressure (Chobanian, 2000). In addition, some observational studies and clinical trials performed in general populations provide overwhelming evidence that higher salt intake is associated with raised blood pressure (He and MacGregor 2007; Law et al., 1991; Midgley et al., 1996). A sodium-reduced diet is frequently recommended for hypertensive individuals. However, low urinary sodium is associated with greater risk of myocardial infarction among treated hypertensive men (Alderman et al., 1995).

\section{Conclusions}

In conclusion, the estimated salt intake from drinking water in this population exceeded recommended limits. The problem of saline intrusion into drinking water has multiple causes and is likely to be exacerbated by climate change-induced sea-level rise. The presence of high levels of salt in drinking water sources in rural coastal Bangladesh is a cause of public health concern and a challenge for the government of Bangladesh. We can hypothesize that increasing salt intake might contribute to the hypertension in pregnancy in coastal Bangladesh, Although, this study had some pit fall of short duration, minimum samples, unequal sample sizes, the results of this study will certainly help the future public health workers to take steps to overcome the situation of adverse effect of salinity in the coastal area of Bangladesh.

\section{Acknowledgements}

We are thankful to the health assistants and laboratory technicians who helped us to conduct the research.

\section{Conflict of interest}

None to declare. 


\section{References}

Alderman MH, S Madhavan, H Cohen, JE Sealey and JH Laragh, 1995. Low Urinary Sodium Is Associated With Greater Risk of Myocardial Infarction Among Treated Hypertensive Men. Hypertension, 25: 11441152.

Calabrese EJ and RW Tuthill, 1981.The influence of elevated levels of sodium in drinking water on elementary and high school students in Massachusetts. Sci. Total Environ., 18: 117-133.

Chobanian AV and M Hill, 2000. National Heart, Lung, and Blood Institute Workshop on Sodium and Blood Pressure: a critical review of current scientific evidence. Hypertension, 35:858-863.

Hallenbeck WH, GR Brenniman and RJ Anderson, 1981. High sodium in drinking water and its effect on blood pressure. Am J Epidemiol, 114: 817-826.

He FJ and GA MacGregor, 2007. Salt, blood pressure and cardiovascular disease. PhysiolBehav, 22: 298-305.

Hosmer DW and S Lemeshow, 2000. Applied Logistic Regression. New York, USA: John Wiley \& Sons, Inc.

Khan A, SK Mojumder, S Kovats and P Vineis, 2008. Saline contamination of drinking water in Bangladesh. Lancet, 37: 13-85.

Khan A, SK Mojumder, S Kovats, and P Vineis, 2008. Saline contamination of drinking water in Bangladesh. Lancet, 371: 385.

Law MR, CD Frost and NJ Wald, 1991. By how much does dietary salt reduction lower blood pressure? I. Analysis of observational data among populations. II. Analysis of observational data within populations. III. Analysis of data from trials of salt reduction. BMJ, 302:811-24.

Midgley JP, AG Matthew, CM Greenwood and AG Logan, 1996. Effect of reduced dietary sodium on blood pressure: a meta-analysis of randomized controlled trials. JAMA, 275: 1590-1597.

MOEF (Ministry of Environment and Forest), 2006. Impact of Sea-Level Rise on Land Use Suitability and Adaptation Options: Coastal Land Zoning in the Southwest. Dhaka, Bangladesh: Ministry of Environment and Forest.

Parry ML, OF Canziani, JP Palutikof, PJ van der Linden and CE Hanson, 2007. Climate Change 2007: Impacts, Adaptation and Vulnerability. Contribution of Working Group II to the Fourth Assessment Report of the Intergovernmental Panel on Climate Change. Cambridge:Cambridge University Press.

Thornburg KL, SL Jacobson, GD Giraud and MJ Morton, 2000. Hemodynamic changes in pregnancy. SeminPerinatol, 24:11-14.

Tran HA, 2005. Biochemical tests in pregnancy. AustPrescr, 28:98-101. 